\title{
ANALISIS PENYEBAB RUSAKNYA CARGO OIL PUMP GUNA MENUNJANG DISCHARGE CARGO PERTAMAX DI ATASKAPAL MT. PATRA TANKER 2
}

\author{
Wahyu Permana Aji \\ Politeknik Bumi Akpelni Semarang \\ e-mail : wahyupurnamaaji12@gmail.com \\ Eka Darmana \\ Politeknik Bumi Akpelni Semarang \\ e-mail : ekadarmana@akpelni.ac.id.
}

\begin{abstract}
ABSTRAK
Pada saat melakukan discharge cargo pertamax di Pelabuhan pada pukul 10.25 waktu setempat, masinis jaga mendapat informasi dari cargo control room bahwa telah terjadi masalah, masinis jaga segera menuju ke cargo pump room untuk mengecek keadaan cargo oil pump. Masinis jaga melihat kebocoran pada pump room yang mengakibatkan keadaan pump room penuh dengan ceceran minyak pertamax yang di angkut oleh kapal. Kebocoran minyak dari cargo oil pump sangat menggangu proses discharge cargo dan akan berpotensi menimbulkan bahaya sehingga perlu dilakukan analisis, mengingat pengoperasian dan pelaksanaan maintenance selama ini sudah sesuai standart operational procedure (SOP). Penelitian ini berdasarkan studi kasus pada kapal MT. Patra Tanker 2. Metode pengumpulan data dilakukan dengan observasi langsung dikapal tersebut selama satu tahun kemudian melakukan diskusi dan wawancara dengan kru kapal yang bertanggung jawab pada cargo pump, serta data-data dari literatur seperti instruction manual, SOP, maupun jurnal penelitian. Pendekatan analisis dilakukan secara diskriptif kualitatif terhadap kerusakan cargo oil pump berdasarkan data dan berbagai literatur yang digunakan sebagai rujukan ataupun pembanding. Dari hasil analisis dinyatakan bahwa penyebab rusaknya cargo oil pump disebabkan karena pengaruh dari kualitas mechanical seal tidak memenuhi standart, ball bearing rusak atau aus pada cargo oil pump, shaft sleeve ceramic (bushing) menipis atau aus, dan kerusakan pada shaft (poros) cargo oil pump. Penyebab kerusakan pada cargo oil pump dapat dihindari dengan cara melaksanakan perawatan secara rutin dan pengontrolan secara berkala saat cargo oil pump sedang bekerja (running).
\end{abstract}

Kata kunci: Cargo oil pump, Discharge cargo pertamax, Loading cargo, Mechanical seal, Shaft sleeve ceramic 


\begin{abstract}
When discharging the Pertamax cargo at the port at 10:25 a.m. local time, the on-duty engineer received information from the cargo control room that a problem had occurred, the engineer immediately went to the cargo pump room to check the condition of the cargo oil pump. The engineer is see a leak in the pump room which causes the pump room to be full of spills of Pertamax oil transported by the ship. This research is based on a case study on the ship MT. Patra Tanker 2. The data collection method was carried out by direct observation on the ship for one year and then conducted discussions and interviews with the ship's crew responsible for the cargo pump, as well as data from literature such as instruction manuals and standard operational procedures (SOP). The analysis approach was carried out in a descriptive qualitative manner based on data and various literatures used as a reference or comparison. From the results of the analysis it is stated that the cause of the damage to the cargo oil pump is due to the influence of the quality of the mechanical seal that does not meet the standard, the ball bearing is damaged or worn on the cargo oil pump, the ceramic sleeve shaft (bushing) is thinning or worn, and damage to the cargo oil pump shaft. The cause of damage to the cargo oil pump can be avoided by carrying out routine maintenance and controlling it regularly when the cargo oil pump is running.
\end{abstract}

Keywords: Cargo oil pump, Pertamax discharge cargo, loading cargo, mechanical seal, ceramic sleeve shaft 


\section{Pendahuluan}

Pompa merupakan salah satu permesinan di atas kapal yang mempunyai peranan penting. Secara umum fungsi pompa adalah untuk memindahkan cairan dari tempat yang bertekanan rendah ke tempat yang bertekanan lebih tinggi atau menaikan cairan dari permukaan rendah ke permukaan yang lebih tinggi (Muhammad \& Jawwadi, 2018). Kelancaran dalam pengoperasian kapal yang selalu di tuntut agar pengoperasiaannya tepat waktu, dikarenakan tuntutan oleh perusahaan dari segi ekonomi yaitu dengan tibanya kapal tersebut tepat pada waktu yang sudah dijadwalkan serta ketepatan waktu pada saat discharging cargo ataupun loading cargo diharapkan oleh perusahaan pemilik kapal dan juga perusahaan pemilik muatan (Ahmad mustochri, 2021).

Berdasarkan observasi selama satu tahun di atas kapal MT. Patra Tanker 2, beberapa kali mengalami suatu masalah atau gangguan, pada saat kapal sandar di pelabuhan TBBM (Terminal Bahan Bakar Minyak) Pertamina Pontianak, sekitar pukul 10.25 waktu setempat masinis jaga mendapat informasi dari cargo control room bahwa telah terjadi masalah pada proses discharge cargo pertamax, masinis jaga segera menuju ke cargo pump room untuk mengambil tindakan dengan melakukan pengecekan terhadap cargo oil pump, saat memasuki cargo pump room masinis jaga melihat banyak muatan pertamax tercecer sehingga cargo pump room tergenang muatan pertamax yang di angkut oleh kapal MT. Patra Tanker 2. Maka perlu dilakukan analisis terhadap kasus tersebut

Pada zaman modern ini alat transportasi sangat berpengaruh penting untuk pengiriman barang khususnya transportasi laut yang menjadi pilihan utama untuk pengangkutan barang baik antar pulau, antar negara, maupun antar benua sehingga perusahaan pelayaran sebagai penyedia jasa angkutan barang bersaing untuk menjadi yang terbaik. Kapal adalah suatu moda transportasi laut atau sungai untuk mengangkut penumpang dan/atau barang dalam jumlah banyak baik berupa muatan padat hingga muatan yang sifatnya cair maupun gas. MT. Patra Tanker 2 adalah kapal tanker clean oil product atau dapat juga disebut dengan kapal tangki pengangkut minyak yang sudah di olah menjadi minyak produk.

Pompa adalah sebuah alat yang digunakan untuk memindahkan suatu cairan/fluida dari suatu tempat ke tempat lain dengan cara membuat perbedaan tekanan antara bagian masuk (suction) dengan bagian keluar (discharge) (Pratomo, 2015). Pompa dapat menaikkan cairan dari permukaan rendah ke permukaan yang lebih tinggi atau memindahkan cairan dari tempat yang bertekanan rendah ke tempat yang bertekanan lebih tinggi (Sumarno P.S. et al., 2018). Pompa merupakan salah satu dari sekian banyak permesinan bantu diatas kapal,

Pada kapal-kapal tanker, cargo pump merupakan hal yang sangat penting dan menentukan dalam rangka memperlancar operasi kapal, terutama dalam proses bongkar muat baik di terminal maupun transfer antara kapal dengan kapal. Apabila terjadi sesuatu pada cargo pump maka proses bongkar muat dan juga operasional kapal bisa terganggu atau berubah dan biaya semakin bertambah. Cargo pump biasa digunakan untuk membongkar muatan cair yang dimuat kapal-kapal tanker pada umumnya seperti halnya product oil dan crude oil yang ada pada tangki muatan kapal (Supriyadi \& Darmana, 2021). Pompa cargo tidak dapat bekerja sendiri melainkan harus ada tenaga yang menggerakannya. Mengenai tenaga ini dapat digunakan berbagai macam tenaga. Tenaga-tenaga yang digunakan itu disesuaikan dengan keperluan dan fungsinya dari pompa-pompa.

1. Motor listrik, untuk kecepatan tinggi atau rendah.

2. Mesin uap, untuk kecepatan rendah.

3. Motor diesel, untuk kecepatan tinggi atau rendah.

4. Turbin uap, untuk kecepatan tinggi.

Pemilihan jenis-jenis pompa diatas kapal untuk sistem tergantung pada kekentalan (viscosity) zat cair dan karateristik dari zat cair yang ingin dipompa atau di sirkulasikan. Karateristik zat cair dalam sistem seperti tingkat cairan yang berbeda diantaranya, cairan yang akan dipompa, suhu zat cair di sistem, dan tekanan fluida dalam sistem. Karna karaktersitik zat cair diatas kapal berbeda-beda maka digunakan jenis-jenis pompa yang berbeda-beda pula. Pada dasarnya, cairan apapun dapat ditangani oleh hampir semua jenis 
pompa, namun pemilihannya harus disesuaikan dengan vikositas cairan dan perbedaan elevasi (Anomin, 2014). Secara garis besar pompa digolongkan menjadi 2 jenis, yaitu:

1. Pompa Pemindah Positif (Positive Displacement Pump)

a. Recripocating pump

b. Rotary pump

2. Pompa Pemindah Tidak Positif (Non Positive Displacement pump)

a. Centrifugal pump

Dalam pengaplikasiannya di lapangan, pompa sentrifugal dianggap lebih ekonomis dan lebih banyak digunakan bila dibandingkan dengan pompa rotary dan reciprocating.

MT. Patra Tanker 2 merupakan kapal clean oil product yang menggunakan pesawat bantu pompa sentrifugal, sebagai pompa cargo untuk kegiatan membongkar muatan minyak pertamax. Dari kapal menuju ke Pelabuhan TBBM (Terminal Bahan Bakar Minyak) untuk di distribusikan ke seluruh kota Pontianak dan sekitarnya.

Pompa sentrifugal merupakan salah satu jenis pompa dinamis. Pompa ini mendorong fluida dengan arah tegak lurus dari poros impeller pompa. Pompa sentrifugal digerakkan oleh motor, daya dari motor diberikan kepada poros pompa untuk memutar impeller yang dipasangkan pada poros tersebut. Zat cair yang ada dalam impeller akan ikut berputar karena dorongan sudu-sudu, karena timbulnya gaya sentrifugal, maka zat cair mengalir dari tengah impeller keluar melalui saluran diantara sudu dan meninggalkan impeller dengan kecepatan yang tinggi. Zat cair yang keluar dari impeller dengan kecepatan tinggi ini kemudian mengalir melalui saluran yang penampangnya makin membesar (volute/diffuser), sehingga terjadi perubahan dari head kecepatan menjadi head tekanan. Maka zat cair yang keluar dari flens keluar pompa, bertambah besar head totalnya. Pengisapan terjadi karena setelah zat cair dilemparkan oleh impeller, ruang diantara sudu-sudu menjadi vakum sehingga zat cair akan terisap masuk.

Pompa sentrifugal memiliki beberapa kelebihan dibandingkan pompa reciprocating, antara lain biaya maintenance (perawatan) dapat dikatakan terjangkau, menghjasilkan aliran fluida yang lebih kontinyu bila dibandingkan dengan pompa reciprocating yang alirannya tersendat-sendat (intermitten), mempunyai tingkat keausan lebih kecil karena tidak terjadi gesekan antara impeller dengan rumah pompa, suction heat cairan yang besar dibandingkan dengan jenis pompa bolak-balik (Setyo, 2018).

\section{Metode}

Penelitian ini berdasarkan studi kasus yang terjadi di kapal MT. Patra Tanker 2 (gambar 1) yang memuat pertamax.

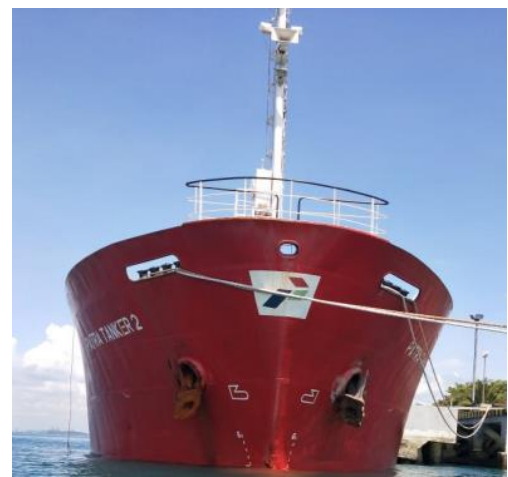

Gambar 1. Kapal MT. Patra Tanker 2

(Sumber : Hasil Observasi) 
Nama Perusahaan :PT. Pertamina Transkontinental

$\begin{array}{ll}\text { Nama Kapal } & \text { : MT. Patra Tanker } 2 \\ \text { Jenis Kapal } & \text { : Tanker } \\ \text { Reg. Pelabuhan } & \text { : Jakarta } \\ \text { Gross Tonnage } & : 2770 \mathrm{~T} \\ \text { Nett Tonnage } & : 1165 \mathrm{~T} \\ \text { Bendera } & : \text { Indonesia } \\ \text { Cargo Pump No. } & : \text { :97-20134 to 97-20136 }\end{array}$

Pengumpulan data dilakukan dengan observasi langsung dikapal tersebut dan sebagai obyek penelitian adalah cargo oil pump (gambar 2). Hal ini dimaksudkan untuk memperoleh data sebanyak-banyaknya tentang rusaknya cargo oil pump.

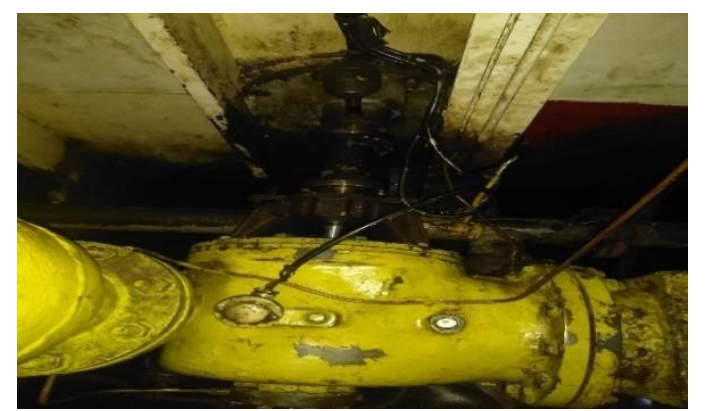

Gambar 2. Cargo oil pump kapal MT. Patra Tanker 2

(Sumber : Hasil Observasi)

Kemudian melakukan diskusi atau wawancara dengan pada crew kapal yang bertanggungjawab pada cargo oil pump. Wawancara dilakukan kepada seluruh crew mesin di kapal terutama KKM (Chief Engineer) dan masinis untuk memperoleh data rusaknya cargo oil pump dan data pelaksanaan standard operational procedure (SOP). Data juga diperoleh dari berbagai literatur baik instruction manual, SOP menjalankan cargo oil pump pada saat discharge cargo pertamax maupun artikel yang terkait. Dengan terkumpulnya data yang valid maka dengan mudah akan membantu dalam proses pengolahan data sehingga akan didapatkan hasil pemecahan masalah tepat sebagaimana yang diharapkan.

Pendekatan analisis yang dilakukan yaitu dengan comparative terhadap pelaksanaan SOP kemudian diskriptif kualitatif terhadap kerusakan cargo oil pump berdasarkan pengolahan dari data-data yang diperoleh dari pengamatan serta informasi erbagai sumber maupun dari berbagai literatur, artikel-artikel ilmiah sebagai pembanding.

\section{Hasil Dan Pembahasan}

Dari hasil observasi didapatkan bahwa cargo oil pump mengalami kebocoran pada saat discharge cargo pertamax di Pelabuhan TBBM (Terminal Bahan Bakar Minyak ) Pertamina Pontianak. Cargo oil pump mengalami rembesan minyak pertamax dari shaft (poros) sebagaimana terlihat pada gambar 3. Disatu sisi berdasarkan data dilapangan, pelaksanaan pengoperasioan system cargo oil pump sudah sesuai dengan SOP. 


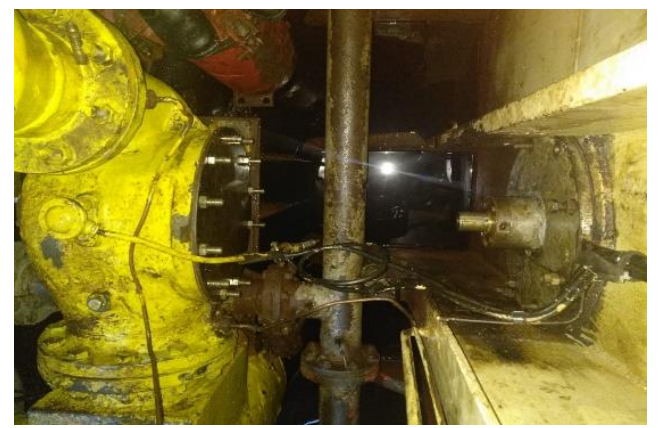

Gambar 3. Cargo pump bocor

(Sumber : Hasil Observasi)

Karena semakin banyaknya ceceran minyak yang menggenang di dalam cargo pump room. Mengakibatkan discharge cargo pertamax yang berjalan normal menjadi terkendala dan membutuhkan waktu yang lama. Dari pengolahan data-data yang diperoleh maka dapat dianalisis mengenai penyebab terjadinya kebocoran tersebut. Kemungkinan Unsur-unsur penyebab rusaknya cargo oil pump adalah:

Kualitas dari mechanical seal tidak memenuhi standart. Seperti diketahui bahwa kualitas mechanical seal sangat penting untuk proses discharge cargo pertamax pada cargo oil pump. Dengan kualitas mechanical seal yang kualitasnya kurang memenuhi standart dapat menyebabkan mempercepat rusaknya atau umur pendek (Maryanti, 2014) dan terjadi kebocoran pada cargo oil pump serta dapat menyebabkan tergenangnya cargo pump room oleh muatan minyak pertamax yang di angkut oleh kapal MT. Patra Tanker 2, rusaknya mechanical seal cargo oil pump ini disebabkan oleh:

1. Kotornya mechanical seal.

Kotornya mechanical seal di pengaruhi oleh muatan minyak pertamax pada kapal yang masuk ke dalam cargo oil pump. Karena muatan minyak pertamax yang tidak bersih atau terdapat kotoran masuk ke dalam cargo oil pump, maka kotoran tersebut akan menempel di sekitar dinding pada mechanical seal dan dalam jangka waktu yang agak lama dengan adanya gesekan antara mechanical seal dengan shaft (poros) tersebut. Yang mengakibatkan terjadinya kebocoran pada dinding seal tersebut, yang akhirnya membuat celah yang lebar antara mechanical seal dengan shaft (poros).

2. Strainer yang tidak sesuai

Kerusakan pada mechanical seal disebabkan karena strainer atau saringan (Ahmad mustochri, 2021) yang digunakan untuk menyaring muatan minyak yang di hisap oleh cargo oil pump tidak memenuhi dengan kriteria atau ukuran lubang pada saringan sebagaimana mestinya. Sehingga muatan minyak pertamax yang berada di dalam tangki kapal tanker MT. Patra Tanker 2 membawa kotoran yang mengendap pada dasar tangki muatan kapal.

Dudukan atau memasangan ball bearing yang tidak rata sangat mempengaruhi menurunnya kinerja dari ball bearing (Kogelahar, 2019) terhadap kinerja cargo oil pump, tenaga yang di peroleh dari electromotor menjadi terreduksi ketika shaft (poros) yang menerima putaran dari electromotor untuk di terus akan menuju ke impeller menjadi berat dan lambat. Ball bearing yang tidak pernah di rawat dengan memberi grease, akan mengalami usia yang tidak lama dan mudah aus, karena minimnya spare part yang dikirim dari perusahaan dan susahnya permintaan barang dari crew mesin kapal ke kantor, maka sangat penting untuk melakukan perawatan rutin pada bearing.

Shaft sleeve ceramic (bushing) yang menipis atau aus dapat di sebabkan karena bahan dari komponen tersebut yang tidak memenuhi standart atau imitasi. Crew mesin kapal juga dituntut untuk bisa membuat atau membubut bushing yang bermaterial carbon ceramic jika shaft sleeve ceramic (bushing) di butuhkan pada saat cargo oil pump rusak dan ketika spare part tersebut telah habis atau tidak tersedia di dalam strore penyimpanan. Pada saat cargo oil pump running (beroperasi) dengan kecepatan tinggi, gesekan komponen yang bersentuhan langsung seperti shaft (poros) dengan shaft sleeve ceramic (bushing) dapat 
mengakibatkan kerusakan atau aus pada shaft sleeve ceramic (bushing), oleh sebab itu bahan atau material yang di pakai pada shaft sleeve ceramic (bushing) harus sesuai standart/diperkeras (Wiendarto, 2008) untuk cargo pump dengan kecepatan tinggi.

Shaft (poros) merupakan komponen yang sangat penting pada bagian cargo oil pump, poros merupakan merupakan rotary part pompa sentrifugal yang sering mengalami kerusakan sebagai dampak tingginya kecepatan putaran pompa. Poros berfungsi untuk meneruskan momen puntir dari penggerak selama beroperasi, kegagalan atau kerusakan pada poros pompa dapat diakibatkan karena konsentrasi tegangan, gesekan antara poros dengan mechanical seal maupun bushing, dan juga pemilihan bahan atau material yang tidak tepat untuk jenis pompa yang digunakan pada kapal, poros pompa dapat mengalami patah jika digunakan melebihi batas jam kerja dan menerima beban puntir yang terlalu besar, dan dapat mengakibatkan terhambatnya proses discharge cargo pertamax pada kapal.

Cara mengatasi penyebab rusaknya cargo oil pump:

1. Perawatan berkala (Betoky, 2017) terhadap cargo oil pump.

Pemeriksaan dan pengecekan serta perawatan harus di lakukan dengan melihat jam kerja dari cargo oil pump yang di sesuaikan pada instruction manual book dan pengecekansecara lokal pada cargo oil pump dengan melihat secara langsung ke objek yang diamati.

2. Penanganan pada cargo oil pump karena muatan minyak yang kotor.

Adapun hal-hal yang perlu diperhatikan dalam melaksanakan penanganan perbaikan cargo oil pump yang rusak karena muatan minyak yang tidak tersaring pada strainer atau saringan dapat menyebabkan kotoran akan menempel pada casing cargo oil pump.

3. Kotoran yang mengendap.

Akan menimbulkan kerak pada impeller dan casing, cara mengatasinya antara lain sebagai berikut:

a. Lakukan pemeriksaan pada saringan atau strainer yang di lalui muatan minyak pertamax pada saat discharge cargo pertamax. Periksa keadaan casing cargo oil pump dengan cara membongkar bagian komponen satu-persatu dengan hati-hati, apakah terdapat kerak-kerak yang mengendap pada casing cargo oil pump.

b. Bersihkan strainer atau saringan yang di lalui oleh muatan minyak pertamax dari tangki kapal menuju ke cargo oil pump. Lalu bersihkan pada bagian dalam casing pompa dengan menggunakan kain majun hingga bersih.

c. Setelah casing cargo oil pump bersih, lalu pasang kembali komponen-komponen tersebut hingga benar dan tidak ada yang tertinggal.

4. Menetesnya muatan minyak pertamax melalui mechanical seal dan shaft.

Penanganan terhadap adanya muatan minyak pertamax yang menetes pada mechanical seal dan shaft adalah dengan mengganti mechanical seal dengan spare part yang ada di store penyimpanan. antara mechanical seal dengan shaft (poros) yang bocor. Hal itu terjadi karena adanya gesekan antara mechanical seal yang kotor dengan shaft (poros) akan menimbulkan celah yang mengakibatkan rembesan pada mechanical seal dan menyebabkan kebocoran pada cargo oil pump. Adapun langkah langkah yang dilakukan untuk menangani kebocoran pada mechanical seal dan shaft, antara lain sebagai berikut:

a. Buka atau lepas semua nut (mur) yang ada pada shaft coupling maupun pada body atau casing cargo oil pump.

b. Ketika semua komponen telah di bongkar satu-persatu, selanjutnya bongkar komponen yang berada di dalam cargo oil pump.

c. Ketika shaft dan impeller telah selesai di keluarkan dari casing, lepas mechanical seal, shaft sleeve ceramic (bushing), dan ball bearing yang terpasang pada shaft cargo oil pump.

d. Lakukan penggantian komponen-komponen pada cargo oil pump, seperti: mechanical seal, shaft sleeve ceramic (bushing), ball bearing, dan shaft (poros) yang telah rusak akibat jam kerja yang berlebihan. 
e. Pasang komponen-komponen sesuai dengan urutan saat pembongkaran atau overhaul cargo oil pump, dan pastikan kembali bahwa ball bearing di beri grease terlebih dahulu sebelum di pasang ke shaft (poros) yang baru agar poros tidak mengalami lecet maupun bengkok.

\section{Kesimpulan}

Berdasarkan pembahasan atau analisis diatas dapat ditarik kesimpulan dan sekaligus menjadi saran yang mungkin dapat berguna bagi pihak kapal maupun pihak perusahaan bahwa penyebab terjadinya gangguan dan kerusakan pada cargo oil pump antara lain: kualitas mechanical seal tidak standard sehingga lebih mempercepat rusaknya ketika terkena kotoran yang terkandung di muatan minyak pertamax; strainer dengan ukuran lubang-lubang tidak sesuai standardnya sehingga kotoran lolos; ball bearing tidak rata/rusak; Shaft sleeve ceramic menipis dan aus; dan kerusakan pada shaft (poros) cargo oil pump.

Penanganan terhadap cargo oil pump yaitu dengan melakukan pemeriksaan, perawatan secara rutin serta perbaikan yang dilakukan harus dengan ketelitian dan menjaga kebersihan bagian-bagian yang dibongkar, tidak boleh berserakan didalam cargo pump room melainkan diletakkan pada tempat tertentu yang dianggap layak, dan sebelum dipasang kembali ke bagian- bagiannya sebaiknya di bersihkan terlebih dahulu dengan menggunakan kain lap (majun). Pastikan cargo oil pumptidak ada lagi yang mengalami kerusakan maupun kebocoran pada saat di jalankan (running).

Penanganan terhadap spare part yang kurang memenuhi standart (imitasi), seharusnya perusahaan pemilik kapal menyiapkan stok spare partcargo oilpump sesuai dengan spesifikasi dari cargo oil pump tersebut. Agar tidak terjadi kerusakan pada cargo oil pump karena spare part yang dipakai tidak sesuai standart (imitasi).

Chief Engineer dapat menekankan kepada para masinis dan oiler untuk lebih intensif dalam melakukan perawatan dan pengecekan secara rutin terhadap cargo oil pump, sehingga kerusakan dan kebocoran dari setiap bagian-bagian komponen cargo oil pump dapat diatasi segera mungkin.

Perusahaan diharapkan memenuhi permintaan spare part/suku cadang, agar tidak terjadi kekurangan dalam perbaikan dari cargo oil pump di atas kapal.

\section{Daftar Pustaka}

Ahmad mustochri. (2021). Rusaknya mechanical seal terhadap pengoperasian cargo oil pump pada MT. Pegaden. Politeknik Ilmu Pelayaran Semarang.

Anomin. (2014). Jenis-Jenis Pompa Berdasarkan Cara Kerjanya Mengalirkan Fluida. https://www.prosesindustri.com/2014/12/jenis-jenis-pompa-berdasarkan-cara-kerjanya-mengalirkanfluida.html

Betoky, M. C. (2017). Pengoperasian Dan Pemeliharaan Pompa Sentrifugal P-100 / 5 Feed Di Kilang Ppsdm Migas Cepu.

Kogelahar. (2019). Tiga cara pemasangan bearing yang benar. https://www.kogelahar.com/tiga-carapemasangan-bearing-yang-benar/

Maryanti, B. (2014). Pengaruh Kondisi Operasional Terhadap Umur Pakai Mechanical Seal Pada Pompa Sentrifugal. Teknik Mesin Fakultas Teknologi Industri Universitas Balikpapan., 10, 1-6.

Muhammad, A., \& Jawwadi, B. (2018). Teknik Analisa Perbedaan Diameter Suction Pada Pompa Sentrifugal Merek Prima Tipe Poros Horisontal. 07, 44-52.

Pratomo, M. (2015). Jenis-Jenis Pompa. In Universitas Diponegoro.

Setyo, W. G. (2018). Perencanaan Ulang Impeller Pompa Sentrifugal Dengan Fluida Kerja Air Bersih Pada Unit IPA Plosowahyu PDAM Lamongan. Institut Teknologi Sepuluh Nopember Surabaya. 
Sumarno P.S., Dwi Prasetyo, \& Saiful Hadi Prasetyo. (2018). Identifikasi Penyebab Kerusakan Seal Cargo Pump Dalam Proses Discharging Muatan Kimia Cair. Dinamika Bahari, 8(2), 2045-2062. https://doi.org/10.46484/db.v8i2.75

Supriyadi, A., \& Darmana, E. (2021). Analisa Terhambatnya Proses Discharge Pada Cargo Pump. 1(2), 8490.

Wiendarto, A. (2008). Mengapa mechanical seal bocor. https://mechanicalseal.wordpress.com/problematikamechanicalseal/mengapa-mechanicalsal-bocor/ 
ISSN : 1412-6826 e-ISSN : 2623-2030 